\title{
cDNA cloning, characterization, and pharmacologic evaluation of anticancer activity of a lectin gene in Pinellia integrifolia
}

\author{
L.L. Liu ${ }^{1,2}$, Z.J. Yang ${ }^{1}$ and Z.S. Peng ${ }^{1}$ \\ ${ }^{1}$ Key Laboratory of Southwest China Wildlife Resources Conservation, \\ Ministry of Education, China West Normal University, Sichuan, Nanchong, \\ China \\ ${ }^{2}$ Key Laboratory of Biorheological Science and Technology, \\ Ministry of Education, Chongqing University, Chongqing, China \\ Corresponding author: Z.J. Yang \\ E-mail: yangzaijun1@126.com
}

Genet. Mol. Res. 15 (3): gmr.15038516

Received February 1, 2016

Accepted March 21, 2016

Published August 12, 2016

DOI http://dx.doi.org/10.4238/gmr.15038516

Copyright $(2016$ The Authors. This is an open-access article distributed under the terms of the Creative Commons Attribution ShareAlike (CC BY-SA) 4.0 License.

\begin{abstract}
Plant lectins are proteins that possess at least one non-catalytic domain, which could reversibly bind to specific monosaccharides or oligosaccharides. The important roles played by plant lectins in immune regulation, signaling pathways, and plant defense could be attributed to their specific binding activities with carbohydrates. In this study, a Pinellia integrifolia lectin gene, designated pia, was cloned using rapid amplification of cDNA ends. The open reading frame (ORF) of pia was constructed into the pET-28a vector, and a $33-\mathrm{kDa}$ recombinant protein was induced in Escherichia coli BL21. The hemagglutination and anticancer properties of the purified recombinant protein were assayed in vitro. The results indicated that the full-length cDNA of pia was 1210 bp long, containing an 807-bp ORF
\end{abstract}


encoding a 268-amino acid peptide. The putative $P$. integrifolia lectin protein (PIA) contained three mannose-binding sites. The agglutinating activity exhibited by PIA was inhibited by D-mannose. PIA was also shown to exert an anti-proliferative activity against nasopharyngeal carcinoma, human cervical carcinoma, and human breast cancer cell lines in vitro. These results could be applied to determine the function of PIA in the future.

Key words: Pinellia integrifolia; Pinellia integrifolia lectin (PIA); cDNA cloning; Anticancer

\section{INTRODUCTION}

Lectins are carbohydrate-binding proteins that possess at least one non-catalytic domain, and that can reversibly bind to specific monosaccharides or oligosaccharides (Peumans and Van Damme, 1995). Lectins are extensively distributed in the biosphere and can be found in almost all living organisms, such as plants, viruses, bacteria, invertebrates, and vertebrates, including mammals (Carlini and Grossi-de-Sá, 2002). Plant lectins are the most thoroughly investigated type of lectins. A large number of studies show that most plant lectins play a role in defending the plant against different kinds of plant-eating organisms (Zhen et al., 2002). Mannose-binding lectins (MBLs) are extensively distributed in monocot families such as Alliaceae, Araceae, Amaryllidaceae, Liliaceae, Bromeliaceae, and Orchidaceae (Van Damme et al., 2000). Many lectins, particularly those with mannose-binding capacity, possess significant cytotoxic activity and induce apoptosis in many typical tumor cells (Karasaki et al., 2001; De Mejía and Prisecaru, 2005; Kaur et al., 2006). MBLs have been recently isolated from several Pinellia species, including P. ternata (pta) (Yao et al., 2003), P. cordata (pca) (Lin et al., 2008), and P. pedatisecta (ppa) (Lin et al., 2007). Bioactivity studies have shown that a majority of the MBLs purified from Pinellia possess anticancer activities; for example, PTA has been shown to exert an inhibitory effect on human hepatoma SMMC7721 cells (Xu et al., 2012).

Pinellia integrifolia N.E.Br., which belongs to the Araceae family, is endemic to China, and is mainly distributed in Sichuan, Hubei, Anhui, and Chongqing. P. integrifolia is an important traditional Chinese medicinal herb with detoxifying, detumescent, and pain alleviating properties. In this study, the pia gene from $P$. integrifolia was cloned, and a recombinant plasmid containing the cloned gene was constructed, which was successfully expressed in Escherichia coli. The agglutinating activity of the purified protein on rabbit erythrocytes was higher than that of PTA (Liang et al., 2009). The recombinant $P$. integrifolia lectin protein (rPIA) exerts an anti-proliferative activity against human cancer cells in vitro. The aim of this study was to provide scientific data for in-depth research into the function and application of $P$. integrifolia lectin protein (PIA).

\section{MATERIAL AND METHODS}

\section{Plant material and RNA isolation}

P. integrifolia plants were collected from Xuyong in Sichuan, China, and grown in an experimental field at the China West Normal University, Sichuan, China. Young leaves

Genetics and Molecular Research 15 (3): gmr.15038516 
from $P$. integrifolia were collected for RNA extraction, and total RNA was isolated from the leaves using a plant RNA kit (Omega Biotek, Norcross, GA, USA) according to the manufacturer instructions. The RNA quality and concentration was determined by agarose gel electrophoresis and spectrophotometer analysis (Nanodrop 2000; Thermo Fisher Scientific, Waltham, MA, USA). The extracted RNA was stored at $-80^{\circ} \mathrm{C}$ prior to rapid amplification of cDNA ends (RACE) and reverse transcriptase polymerase chain reaction (RT-PCR) analysis.

\section{Molecular cloning of pia full-length cDNA}

Details of primers used in this study are presented in Table 1. Primers P1-F and P1-R, designed according to the conserved regions of $p t a$ from P. ternata and ppa from P. pedatisecta, respectively, were used to amplify the core fragment. The samples $(2 \mu \mathrm{L})$ were subjected to RT-PCR in reaction mixtures prepared using the one-step RT-PCR kit (TaKaRa Bio Inc., Dalian, China). The cycling conditions were set as follows: reverse transcription at $50^{\circ} \mathrm{C}$ for $30 \mathrm{~min}$; initial denaturation at $94^{\circ} \mathrm{C}$ for $2 \mathrm{~min}$; and 35 cycles of amplification (denaturation at $94^{\circ} \mathrm{C}$ for $30 \mathrm{~s}$, annealing at $54^{\circ} \mathrm{C}$ for $30 \mathrm{~s}$, and extension at $72^{\circ} \mathrm{C}$ for $1 \mathrm{~min}$ ). The PCR products were separated on agarose gels, and the target fragment was recovered and purified from the gels using the QIAquick gel extraction kit (Qiagen, Venlo, Netherlands). This was then cloned into the pMD-18T vector (TaKaRa Bio Inc.) and sequenced by Novogene Biotechnology Co. Ltd. (Beijing, China).

Table 1. Primers used in this study.

\begin{tabular}{l|l|l}
\hline Primer & Primer sequence (5'-3') & Purpose \\
\hline P1-F & GCTCAGCCTCACGAAACAG & Core region cloning \\
\hline P1-R & CAGTCGGCACCAACTACCT & Core region cloning \\
\hline 3'RACE Outer & AGGGGCAACTACGCCTTCGTCGTCCAT & 3'RACE \\
\hline 3'RACE Inter & GTCCAACACCCACGGCAACGGCGAGA & 3'RACE \\
\hline 5'RACE Outer & GGACTGCCAGTTGCCGTTGTA & 5'RACE \\
\hline 5'RACE Inter & TACAGGACGGCGTTGCAGTCT & 5'RACE \\
\hline P2-F & CATGGCGAAGCTCCTCCTCTT & ORF cloning \\
\hline P2-R & CCAACTTGGATCGTTTCGCTT & ORF cloning \\
\hline P3-F & CGAATTCATGGCGAAGCTCCTCCTCTT & Recombinant plasmid construction \\
\hline P3-R & CCCAAGCTTTTTATTTCACCTTCTCCGTCAC & Recombinant plasmid construction
\end{tabular}

$\mathrm{RACE}=$ rapid amplification of $\mathrm{cDNA}$ ends; $\mathrm{ORF}=$ open reading frame.

The gene-specific primers for 3'RACE and 5'RACE (3'RACE Outer, 3'RACE Inter, 5'RACE Outer, and 5'RACE Inter) were designed based on the core fragment of pia; samples were prepared for RACE using the SMARTTM RACE cDNA Amplification kit (Clontech, Mountain View, CA, USA) according to the manufacturer protocols. Briefly, the 3'- and 5 '-ready cDNA were synthesized as described by the manufacturer. The first round of PCR for 3'RACE was conducted in a total volume of $50 \mu \mathrm{L}$, containing $2 \mu \mathrm{L}$ 3'-ready cDNA, and 3 'RACE Outer and UPM provided in the kit. The PCR cycling conditions were set as follows: initiation at $95^{\circ} \mathrm{C}$ for $5 \mathrm{~min}$, followed by 35 cycles of amplification $\left(94^{\circ} \mathrm{C}\right.$ for 15 $\mathrm{s}, 68^{\circ} \mathrm{C}$ for $30 \mathrm{~s}$, and $72^{\circ} \mathrm{C}$ for $1 \mathrm{~min}$ ). The first round PCR product was diluted 50 -fold and used as the template for the second round of PCR, conducted with the 3'RACE Inter primer and NUP provided in the kit. The primary 5'RACE PCR was conducted with the 5'-ready cDNA template, 5'RACE Outer primer, and UPM. The PCR program was set according to the manufacturer protocols. The product of the primary PCR was diluted 50-fold and used as the

Genetics and Molecular Research 15 (3): gmr.15038516 
template for the nested PCR conducted with the 5'RACE Inter primer and NUP (provided in the kit). The $3^{\prime} \mathrm{RACE}$ and 5'RACE products were cloned into the pMD-18T vector (TaKaRa Bio Inc.) and sequenced.

The open reading frame (ORF) of pia was deduced by aligning and assembling the core sequence and 5'RACE and 3'RACE sequences using the Vector NTI Suite 9.0; the ORF was obtained via RT-PCR with the primers P2-F and P2-R, using the one-step RT-PCR kit (TaKaRa Bio Inc.). The amplified products were purified and cloned into the pMD-18T vector, and subsequently sequenced.

\section{Bioinformatic analysis}

The lectin sequences from P. ternata (Thunb) Breit. (PTA, AAR27794), P. cordata N.E.Br. (PCA, ABK88277), and P. pedatisecta Schott (PPA, AGV40779), were acquired from GenBank (http://www.ncbi.nlm.nih.gov). Multiple sequences were aligned using DNAMAN (version 6.0). The ORF of pia was predicted using the ORF finder software (http://www.ncbi. nlm.nih.gov/gorf/gorf.html). The PredictProtein web tool (https://www.predictprotein.org/) was used to deduce the basic parameters and secondary structure of the PIA sequence.

\section{Expression of PIA in E. coli}

The ORF fragment corresponding to the PIA polypeptide was generated by PCR amplification, using the primer pair P3-F (containing an EcoRI restriction site) and P3-R (containing a HindIII restriction site) (Table 1). The PCR products were digested with EcoRI and HindIII, and subsequently inserted into the pET28a vector. The constructed recombinant pET28a-pia plasmid was transformed into E. coli BL21. This was grown in Luria-Bertani medium containing $50 \mu \mathrm{g} / \mathrm{mL}$ kanamycin at $37^{\circ} \mathrm{C}$ up to an absorbance $\left(\mathrm{OD}_{600}\right)$ of 0.6 . The culture was induced by $1 \mathrm{mM}$ isopropyl $\beta$-D-1-thiogalactopyranoside. The empty transformed BL21 vector was used as the control. After induction for $0,0.5,1.0,2.0,3.0$, and $4.0 \mathrm{~h}$, the cells were harvested and centrifuged at $8000 \mathrm{~g}$ for $5 \mathrm{~min}$ at room temperature. The rPIA were purified using a His-bond nickel affinity resin column (Qiagen) according to the manufacturer protocols. The protein purity was analyzed by sodium dodecyl sulfate-polyacrylamide gel electrophoresis (SDSPAGE) as described by Yang et al. (2013), using slab gels containing 12\% (w/v) polyacrylamide; the proteins were detected by staining with Coomassie brilliant blue R-250.

\section{Hemagglutination activity and saccharide inhibition assay}

The hemagglutinin activity of rPIA was assayed on 96-well microtiter plates by a serial double dilution method using a previously described method (Kaur et al., 2006) using rabbit erythrocytes. Hemagglutination was inhibited using carbohydrates, with a two-fold serial dilution technique (Xu et al., 2012).

\section{Assay to determine the in vitro anticancer potential of rPIA}

Human nasopharyngeal (CNE), human cervical cancer (HeLa), and human breast cancer (Bcap-37) cell lines were obtained from the Medical Science Center of West China, Sichuan University. The cells were seeded on 96-well micro culture plates at appropriate

Genetics and Molecular Research 15 (3): gmr.15038516 
densities to maintain the exponential phase of growth throughout the duration of the experiment. CNE, HeLa, and Bcap-37 cells were exposed to rPIA at varying concentrations $(0,10,25,50,100$, and $200 \mu \mathrm{g} / \mathrm{mL})$ for $24 \mathrm{~h}$, each concentration was evaluated in six separate wells. At the end of the exposure period, $10 \mu \mathrm{L} \mathrm{CCK} 8$ was added to each well and the plates were incubated for $4 \mathrm{~h}$ at $37^{\circ} \mathrm{C}$. The OD was read using a plate reader (Bio-Rad, Hercules, CA, USA) at a wavelength of $450 \mathrm{~nm}$. This procedure was also conducted in wells containing the media only and the control. The degree of inhibition of cell proliferation was calculated using the following formula:

$$
\text { Growth inhibition }(\%)=(\mathrm{OD} \text { control - OD treated }) / \mathrm{OD} \text { control }
$$

\section{RESULTS}

\section{Cloning and characterization of full-length pia cDNA}

A specific 533-bp fragment was amplified using two degenerated primers, P1-F and P1-R (Figure 1A); nucleotide Basic Local Alignment Search Tool (BLASTn) analysis revealed that this fragment was highly homologous to other plant lectin genes, particularly the pta gene in P. ternata, indicating the fragment to be a partial lectin gene in P. integrifolia (pia). Two gene-specific primer pairs, designed according to the core sequence, were employed for 3'RACE and 5'RACE, which resulted in approximately 0.5 - and $0.3-\mathrm{kb}$ fragments, respectively (Figure 1B and 1C). Finally, the full-length cDNA sequence of pia was assembled using the core sequence, 3'RACE sequence, and 5'RACE sequence. The ORF sequence of pia was amplified by RT-PCR using the gene-specific primers P2-F and P2-R (Figure 1D) and was confirmed by sequence analysis. The full-length cDNA of pia was $1210 \mathrm{bp}$ long, containing a 91-bp 5'-untranslated region (UTR) and a 312-bp 3'-UTR. The ORF of pia was 807-bp long and coded for a deduced 268-amino acid protein. Primary structure analysis using SwissProt/TrEMBL revealed that the molecular mass of the putative PIA protein was $29.3 \mathrm{kDa}$, with a theoretical $\mathrm{pI}$ of 8.86 . This sequence was compared to the previously sequenced $P$. ternata (Thunb) Breit. agglutinin (PTA, AAR27794), P. cordata N.E.Br. agglutinin (PCA, ABK88277), and $P$. pedatisecta Schott (PPA, AGV40779); significant similarities were observed between the putative PIA protein and these sequenced proteins $(83.76,84.87$, and $76.38 \%$ identity, respectively; Figure 2).

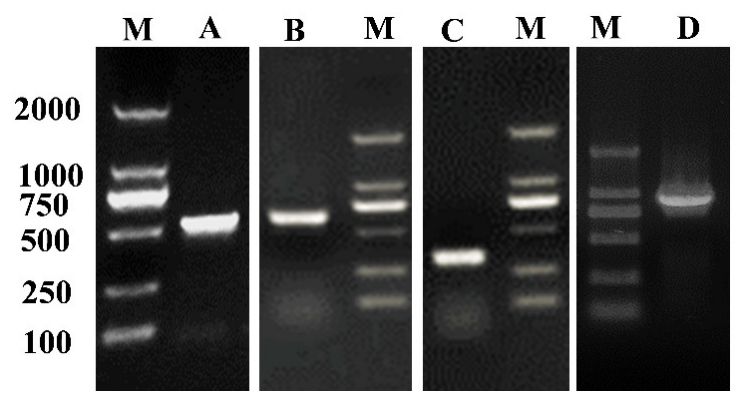

Figure 1. Conserved regions, 3'-rapid amplification of cDNA ends (RACE), 5'-RACE, and open reading frame (ORF) of pta from Pinellia ternate. Lane $M=$ molecular marker DL2000. A. Amplification of conserved regions; B. 3'RACE; C. 5'RACE; and D. ORF amplification. 


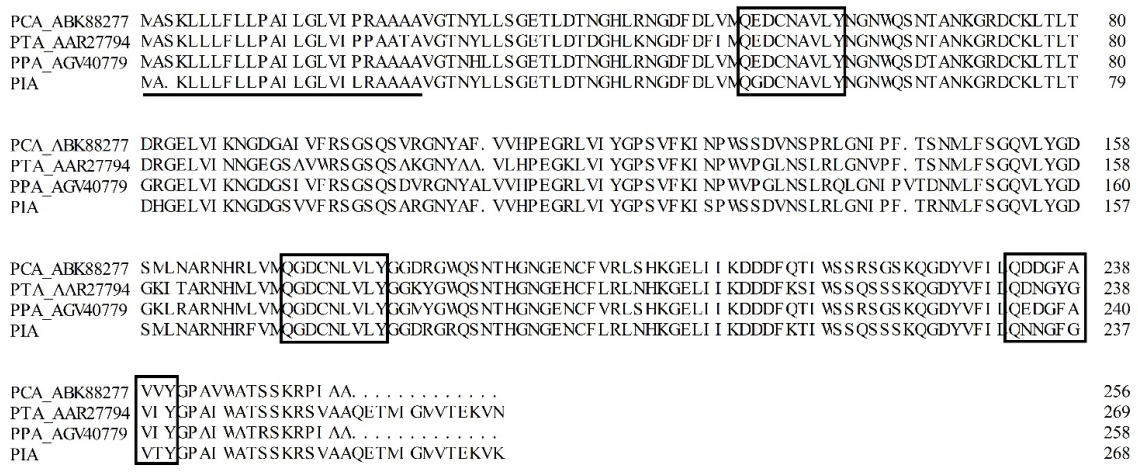

Figure 2. Comparison of amino acid sequences of PCA, PTA, PPA, and PIA. Mannose-binding sites (QXDXNXVXY) are highlighted with boxes and the signal peptide is underlined.

The deduced amino acid sequence coded by the pia gene contains three mannosebinding sites QXDXNXVXY (QDNVY) similar to most lectins from the Araceae species (Lin et al., 2007). The amino acid sequences of site II was the same as those of lectins in the Pinellia species. However, the amino acid sequences of sites I and III differed from those of the Pinellia lectins. Gly substituted for Glu at site I, whereas Asp and Asn were substituted by Asn and Phe, respectively at site III. A 23-amino-acid signal peptide was detected in PIA in accordance with the rules of signal peptide prediction (Petersen et al., 2011). This finding is consistent with most reports on MBLs from the Araceae family (Damme and Peumans, 1998; Fei et al., 2003) (Figure 2). The signal peptide contained highly hydrophobic amino acid residues $(87 \%)$, implying that it was a secretory putative signal peptide.

\section{Overexpression and purification of pia in $E$. coli}

The recombinant vector containing pia was expressed in E. coli BL21. SDS-PAGE showed that the molecular weight of the $\mathrm{N}$-terminal His-tagged PIA protein was approximately $33 \mathrm{kDa}$ (Figure 3A).

A

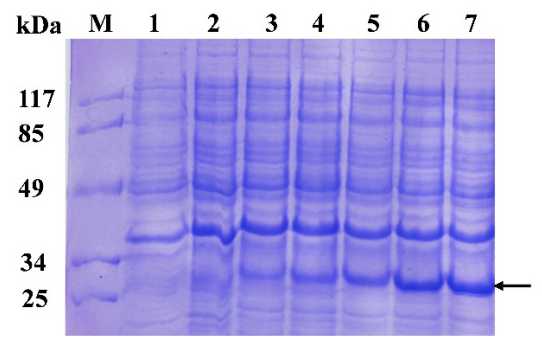

B

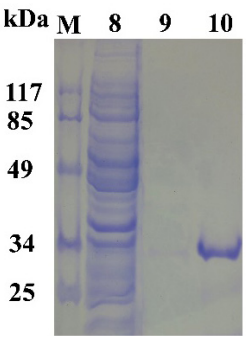

Figure 3. Prokaryotic expression and purification of PIA. A. Protein extracted from recombinant Escherichia coli strains was analyzed by SDS-PAGE stained with Coomassie blue R250. Numbers on the left show the molecular weight, and the arrow indicates the recombinant protein bands induced by IPTG for $0,0.5,1,2,3$, and $4 \mathrm{~h}$ (lane 2-7), respectively. Lane 1 = products of the $E$. coli strains with the empty vectors; B. purification of recombinant PIA protein. Lanes 8, 9, and 10 represent proteins extracted from recombinant $E$. coli, effluent liquid collected from columns, and the eluent collected from columns, respectively.

Genetics and Molecular Research 15 (3): gmr.15038516 
rPIA was expressed after $1 \mathrm{~h}$ of induction and attained the highest level after $4 \mathrm{~h}$. The obtained product was purified for further functional analysis. The rPIA was purified by Hisbond Ni Affinity Resin column after $4 \mathrm{~h}$ of induction (Figure 3B).

\section{Hemagglutination activity and saccharide inhibition assay}

A hemagglutination activity assay was conducted on V-bottomed 96-well microtiter plates in $100 \mu \mathrm{L}$ reaction mixtures comprising equal volumes of a $2 \%$ suspension of rabbit erythrocytes (washed thrice in $0.9 \%$ sodium chloride) and a two-fold serial dilution of rPIA. These mixtures were incubated at room temperature for $1.5 \mathrm{~h}$, and the cells were observed under an inverted microscope. The cells showed obvious agglutination at a minimum rPIA concentration (required to agglutinate rabbit erythrocytes) of $4.7 \mu \mathrm{g} / \mathrm{mL}$.

The hemagglutinating activity was inhibited by adding two-fold serial dilution of several sugars (D-mannose, D-glucose, maltose, D-fructose, and D-galactose) to the incubation mixtures, as mentioned in a previous study. The results showed that the agglutinating activity of rPIA could be inhibited by $72 \mathrm{mM}$ D-mannose, but not by D-glucose, maltose, D-fructose, and D-galactose, even at final concentrations of $400 \mathrm{mM}$.

\section{In vitro anticancer activity of rPIA protein}

The anticancer activity of rPIA was assessed in CNE, HeLa, and Bcap-37 cells cultured in the presence and absence of various concentrations $(10-200 \mu \mathrm{g} / \mathrm{mL})$ of rPIA for 24 $\mathrm{h}$. The cells were then assayed with CCK8, which revealed that rPIA inhibited the cell growth in a dose-dependent manner, compared to the control (untreated) cells (Figure 4). The HeLa cells showed the highest inhibition rate $(50.2 \%)$ at an rPIA concentration of $200 \mu \mathrm{g} / \mathrm{mL}$.

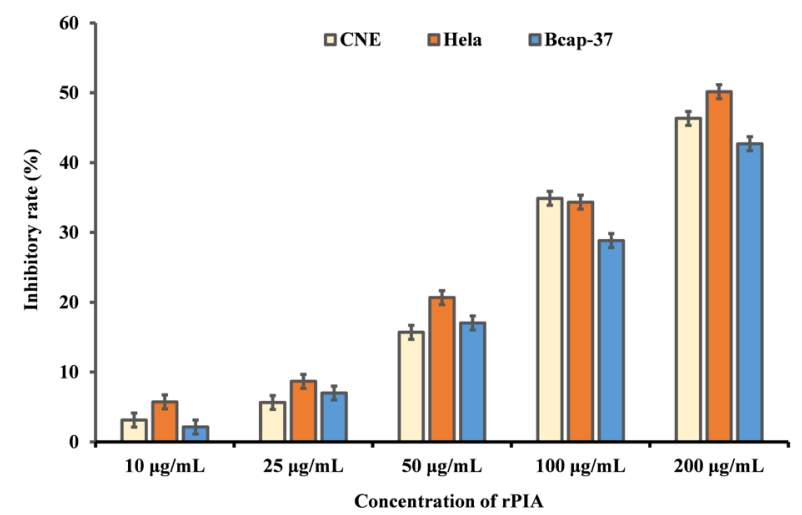

Figure 4. Effect of PIA on the growth of CNE, HeLa, and Bcap-37 cells.

\section{DISCUSSION}

Plant lectins are carbohydrate-binding proteins with non-immune origins that can reversibly bind to carbohydrates, agglutinate cells, or precipitate polysaccharides and glycoconjugates. The important role played by plant lectins in signaling pathways, immune regulation, and plant defense can be attributed to their specific binding activities

Genetics and Molecular Research 15 (3): gmr.15038516 
toward polysaccharides and glycoconjugates (Souza et al., 2013). Plant lectins also possess hemagglutinating, antiviral, and apoptosis-inducing properties, as well as antitumor activities (Liu et al., 2008). Lectins have received considerable attention for their potential therapeutic application in cancer (Sharon and Lis, 2002). Typhonium divaricatum lectin exhibits cytotoxicity against prostatic carcinoma Pro-01 and mastocarcinoma Bre-04 (Luo et al., 2007). Polygonatum cyrtonema lectin also induces apoptosis in cancer cells. P. cyrtonema lectin upregulates Bax and downregulates Bcl-xL and Bcl-2, thereby causing mitochondrial depolarization, cytochrome release, and caspase activation (Liu et al., 2009). PTA has a dosedependent anti-proliferative effect on hepatoma cells SMMC7721 (Xu et al., 2012). Läubli et al. (2014) also reported that lectins effectively inhibit the early development of cancer.

Yao et al. (2003) and Lin et al. (2007) described the pia gene as containing an 807-bp ORF, encoding 268 amino acids. In this study, PIA was predicted to have a signal peptide, and the deduced mature PIA was composed of 245 amino acids, similar to MBLs from other Araceae species such as P. ternata and Colocasia esculenta (Hirai et al., 1993; Yao et al., 2003). A database search using protein BLAST (BLASTp) showed that PIA was highly homologous to MBLs such as PTA (Yao et al., 2003), P. cordata PCA (Lin et al., 2008), and PPA (Lin et al., 2007), indicating that PIA is a member of the monocot MBL superfamily. Sequence analysis revealed three conserved mannose-binding sites (QDNVY) in PIA: the amino acid sequence in site II was identical to that of lectins in Pinellia. However, the amino acid sequences at sites I and III differed from those of Pinella lectins. Whether the residual variation in sugar-binding sites implies a functional enhancement or basic functional shift requires further clarification.

The hemagglutinating activity of refolded $E$. coli PPA against rabbit erythrocytes was approximately four-fold compared to that of E. coli PTA (Liang et al., 2009). This difference could be attributed to the third divergent mannose-binding motif, which differs by four amino acids, or to the 13 amino acids absent in the C-terminus of PTA, which may affect the three-dimensional conformation (Barre et al., 1996). In this study, pia was cloned from $P$. integrifolia and expressed in E. coli cells. The hemagglutination assay revealed that the activity of rPIA was approximately 1.5 times higher than that of $E$. coli PTA (Liang et al., 2009). The inhibitory effect of D-mannan indicated that the biological activity of rPIA could be because of its carbohydrate-binding activity. Additionally, rPIA was shown to inhibit the growth of CNE, HeLa, and Bcap-37 cancer cell lines in vitro. The rate of inhibition of HeLa cells was highest at an rPIA concentration of $200 \mu \mathrm{g} / \mathrm{mL}(50.2 \%)$, indicating that rPIA inhibited cancer cell proliferation in a dose-dependent manner. Furthermore, rPIA exhibited improved anticancer properties compared to rPTA, previously expressed in E. coli by Xu et al. (2012). However, the exact molecular mechanism of the anti-proliferative effect of PIA on cancer cells requires further investigation.

\section{Conflicts of interest}

The authors declare no conflict of interest.

\section{ACKNOWLEDGMENTS}

Research supported by the National Natural Science Foundation of China (Grants \#31301319 and \#31540041) and as a key project of the Chinese Ministry of Education (Grant \#211164).

Genetics and Molecular Research 15 (3): gmr.15038516 


\section{REFERENCES}

Barre A, Van Damme EJ, Peumans WJ and Rougé P (1996). Structure-function relationship of monocot mannose-binding lectins. Plant Physiol. 112: 1531-1540. http://dx.doi.org/10.1104/pp.112.4.1531

Carlini CR and Grossi-de-Sá MF (2002). Plant toxic proteins with insecticidal properties. A review on their potentialities as bioinsecticides. Toxicon 40: 1515-1539. http://dx.doi.org/10.1016/S0041-0101(02)00240-4

Damme EJMV and Peumans WJ (1998). Plant lectins: a composite of several distinct families of structurally and evolutionary related proteins with diverse biological roles. Crit. Rev. Plant Sci. 17: 575-692. http://dx.doi. org $/ 10.1080 / 07352689891304276$

De Mejía EG and Prisecaru VI (2005). Lectins as bioactive plant proteins: a potential in cancer treatment. Crit. Rev. Food Sci. Nutr. 45: 425-445. http://dx.doi.org/10.1080/10408390591034445

Fei J, Liao Z, Chai Y, Pang Y, et al. (2003). Molecular cloning and characterization of a novel mannose-binding lectin gene from Amorphophallus konjac. Mol. Biol. Rep. 30: 177-183. http://dx.doi.org/10.1023/A:1024956525396

Hirai M, Nakamura K, Imai T and Sato T (1993). cDNAs encoding for storage proteins in the tubers of taro (Colocasia esculenta Schott). Jpn. J. Genet. 68: 229-236. http://dx.doi.org/10.1266/jjg.68.229

Karasaki Y, Tsukamoto S, Mizusaki K, Sugiura T, et al. (2001). A garlic lectin exerted an antitumor activity and induced apoptosis in human tumor cells. Food Res. Int. 34: 7-13. http://dx.doi.org/10.1016/S0963-9969(00)00122-8

Kaur M, Singh K, Rup PJ, Kamboj SS, et al. (2006). A tuber lectin from Arisaema jacquemontii Blume with anti-insect and anti-proliferative properties. J. Biochem. Mol. Biol. 39: 432-440. http://dx.doi.org/10.5483/BMBRep.2006.39.4.432

Läubli H, Pearce OM, Schwarz F, Siddiqui SS, et al. (2014). Engagement of myelomonocytic Siglecs by tumor-associated ligands modulates the innate immune response to cancer. Proc. Natl. Acad. Sci. USA 111: 14211-14216. http://dx.doi. org/10.1073/pnas.1409580111

Liang JL, Chen B and Tian XP (2009). Prokaryotic expression and characteristics research of Pinellia ternate and Pinellia pedatisecta lectins. China Biotechnology 29: 80-84.

Lin J, Zhou X, Gao S, Liu X, et al. (2007). cDNA cloning and expression analysis of a mannose-binding lectin from Pinellia pedatisecta. J. Biosci. 32: 241-249. http://dx.doi.org/10.1007/s12038-007-0024-1

Lin L, Lu J, Zeng H, Liang Z, et al. (2008). Molecular cloning and characterization of a mannose-binding lectin gene from Pinellia cordata. Mol. Biol. Rep. 35: 641-647. http://dx.doi.org/10.1007/s11033-007-9134-y

Liu B, Cheng Y, Zhang B, Bian HJ, et al. (2009). Polygonatum cyrtonema lectin induces apoptosis and autophagy in human melanoma A375 cells through a mitochondria-mediated ROS-p38-p53 pathway. Cancer Lett. 275: 54-60. http://dx.doi.org/10.1016/j.canlet.2008.09.042

Liu Z, Liu B, Zhang ZT, Zhou TT, et al. (2008). A mannose-binding lectin from Sophora flavescens induces apoptosis in HeLa cells. Phytomedicine 15: 867-875. http://dx.doi.org/10.1016/j.phymed.2008.02.025

Luo Y, Xu X, Liu J, Li J, et al. (2007). A novel mannose-binding tuber lectin from Typhonium divaricatum (L.) Decne (family Araceae) with antiviral activity against HSV-II and anti-proliferative effect on human cancer cell lines. $B M B$ Reports 40: 358-367.

Petersen TN, Brunak S, Heijne GV and Nielsen H (2011). SignalP4.0: Discriminating peptides from transmembrane regions. Nat. Methods 8: 785-786.

Peumans WJ and Van Damme EJ (1995). Lectins as plant defense proteins. Plant Physiol. 109: 347-352. http://dx.doi. org/10.1104/pp.109.2.347

Sharon $\mathrm{N}$ and Lis H (2002). How proteins bind carbohydrates: lessons from legume lectins. J. Agric. Food Chem. 50: 6586-6591. http://dx.doi.org/10.1021/jf020190s

Souza MA, Carvalho FC, Ruas LP, Ricci-Azevedo R, et al. (2013). The immunomodulatory effect of plant lectins: a review with emphasis on ArtinM properties. Glycoconj. J. 30: 641-657. http://dx.doi.org/10.1007/s10719-012-9464-4

Van Damme EJ, Astoul CH, Barre A, Rougé P, et al. (2000). Cloning and characterization of a monocot mannose-binding lectin from Crocus vernus (family Iridaceae). Eur. J. Biochem. 267: 5067-5077. http://dx.doi.org/10.1046/j.14321327.2000.01563.x

Xu T, Wang B, Wang L, Zhang Y, et al. (2012). Pinellia ternata agglutinin produced in Bombyx mori cells exhibits bioactivity. Acta Biochim. Pol. 59: 231-236.

Yang ZJ, Peng ZS, Wu K and Wei SH (2013). Cloning and characterization of thioredoxin $\mathrm{h}$ in the three-pistil line of common wheat. Genet. Mol. Res. 12: 2688-2701. http://dx.doi.org/10.4238/2013.July.30.7

Yao JH, Zhao XY, Liao ZH, Lin J, et al. (2003). Cloning and molecular characterization of a novel lectin gene from Pinellia ternata. Cell Res. 13: 301-308. http://dx.doi.org/10.1038/sj.cr.7290175

Zhen L, Bo L, Murdock LL and Shade RE (2002). Lectins and protease inhibitors as plant defenses against insects. $J$. Agric. Food Chem. 50: 6605-6611.

Genetics and Molecular Research 15 (3): gmr.15038516 